Canadian

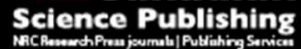

Canadian Journal of Physiology and Pharmacology Revue canadienne de physiologie et pharmacologie

\title{
The apoptotic effect and the plausible mechanism of microwave radiation on rat myocardial cells
}

\begin{tabular}{|r|l|}
\hline Journal: & Canadian Journal of Physiology and Pharmacology \\
\hline Manuscript ID & cjpp-2015-0537.R1 \\
\hline Manuscript Type: & Article \\
\hline Date Submitted by the Author: & 19 -Jan-2016 \\
\hline Complete List of Authors: & $\begin{array}{l}\text { Zhu, Wenhe; Basic medical college, Jilin Medical College } \\
\text { Cui, Yan; First Hospital of Jilin University } \\
\text { Feng, Xianmin; Ji Lin Medical University } \\
\text { Li, Yan; Ji Lin Medical University } \\
\text { Zhang, Wei; Ji Lin Medical University } \\
\text { Xu, Junjie; Ji Lin Medical University } \\
\text { Wang, Huiyan; Ji Lin Medical University } \\
\text { Lv, Shijie; Ji Lin Medical University }\end{array}$ \\
\hline Keyword: & \begin{tabular}{l} 
Microwave radiation, Myocardial call, oxidative stress, energy metabolism \\
\hline
\end{tabular} \\
\hline \multicolumn{2}{|c|}{}
\end{tabular}


The apoptotic effect and the plausible mechanism of microwave radiation on rat myocardial cells

Wenhe Zhu ${ }^{1,}$, Yan Cui ${ }^{2, \text {, }}$, Xianmin Feng ${ }^{1}$, Yan $\mathrm{Li}^{1}$, Wei Zhang ${ }^{1}$, Junjie Xu, Huiyan

Wang $^{1, *}$, Shijie Lv ${ }^{1, *}$

${ }^{1}$ Ji Lin Medical University, Ji Lin 132013, China

${ }^{2}$ First Hospital of Jilin University, Changchun, Jilin, China

\# Equal contribution

* Corresponding author

Department of Biochemistry, Ji Lin Medical University, Ji Lin 132013, China

Huiyan Wang (E-mail: jlmpcwhy@163.com)

Shijie Lv (E-mail: jlmpclsj@163.com)

Tel/Fax: +86-0432-64560460 


\begin{abstract}
Microwaves may exert adverse biological effects on the cardiovascular system at the integrated system and cellular levels. However, the mechanism underlying such effects remains poorly understood. Here we report a previously uncharacterized mechanism through which microwaves damage myocardial cells. Rats were treated with $2450 \mathrm{MHz}$ microwave radiation at $50,100,150$ or $200 \mathrm{~mW} / \mathrm{cm}^{2}$ for $6 \mathrm{~min}$. Microwave treatment significantly enhanced the levels of various enzymes in serum. In addition, it increased the malondialdehyde content while decreasing the levels of antioxidative stress enzymes, activities of enzyme complexes I-IV, and ATP in myocardial tissues. Notably, irradiated myocardial cells exhibited structural damage and underwent apoptosis. Furthermore, western blot analysis revealed significant changes in expression levels of proteins involved in oxidative stress regulation and apoptotic signaling pathways, indicating that microwave irradiation could induce myocardial cell apoptosis by interfering with oxidative stress and cardiac energy metabolism. Our findings provide useful insights into the mechanism of microwave-induced damage to the cardiovascular system.
\end{abstract}

Key word: Microwave radiation, Myocardial call, oxidative stress, energy metabolism 


\section{Introduction}

Microwaves are electromagnetic waves with wavelengths ranging from $1 \mathrm{~mm}$ to $1 \mathrm{~m}$ and frequencies between $300 \mathrm{MHz}$ and $300 \mathrm{GHz}$ (Gupta 2014; Shahin et al. 2013). Microwave technology is widely used in medical research as well as other fields. However, despite their many uses in clinical and household settings, microwaves are known to contribute to environmental pollution to some extent. In particular, the biological effects of electromagnetic waves and their impact on human health are of major concern (Jing et al. 2012; Zuo et al. 2014). Numerous epidemiological surveys and biological experiments have shown that microwave irradiation at intensities high enough to produce heat or non-thermal effects are harmful to an organism.

Microwaves may adversely affect cardiovascular function at the integrated system and cellular levels (Dasdag et al. 2009). It has been reported that the heart is particularly sensitive to microwave radiation, with both its function and structure showing susceptibility to injury (Siddiqi et al. 2013). Since the heart is the most important organ of the circulatory system, any abnormality in the structure or function of the heart is bound to compromise blood supply to all organs. Due to its sensitivity to microwave radiation, the pathological mechanism of heart injury has become a global concern. Furthermore, a certain amount of microwave radiation can induce energy metabolism disorders in myocardial cells, thereby resulting in apoptosis as well as abnormal heart structure and function. Jauchem et al irradiated rats with $38 \mathrm{~mW} / \mathrm{cm} 2$ of $2450 \mathrm{MHz}$ microwaves and found significant heart rate increases in the animals (Jauchem and Frei 1997). They proposed that the temperature gradient in the body of the animal increased during high-frequency microwave irradiation, and that the heart rate significantly increased because of absorption of microwave energy by the tissues. Cardon et al found that long-term irradiation with microwaves at power density of $100 \mu \mathrm{W} / \mathrm{cm} 2$ caused the human cardiovascular system to exhibit functional changes, such as low blood pressure, sinus bradycardia, atrial and ventricular conduction delays, and electrocardiogram waveform changes (Jauchem 1995). By irradiating mice with $10 \mathrm{~mW} / \mathrm{cm} 2$ of $2450 \mathrm{MHz}$ microwave, Zhang et al found that they had altered the oxidative stress balance in myocardial cells and decreased ATP activity 
(Zhang et al. 2012).

Thus, it is well known that microwaves can injure myocardial cells, but precisely how damage occurs has yet to be well understood. Thus, studies on the impacts of microwaves on cardiac energy metabolism of rats and myocardial apoptosis, as well as the underlying mechanisms of microwave damage could open an avenue for determining a sensitive biomarker of microwave-induced damage of the heart. 


\section{Material and methods}

\section{Reagents and Animals}

Creatine kinase (CK), lactate dehydrogenase (LDH), aspartate aminotransferase (AST) and cardiac troponin I (cTnI) diagnostic kits were purchased from Jiancheng Bioengineering Institute (Jiancheng Bioengineering Institute, Nanjing, China). Respiratory Chain Complexes I, II, III, and IV diagnostic kits were purchased from Genmed Scientifics (Genmed Scientifics Inc, U.S.A). Anti-JNK, p-JNK, anti-ERK, p-ERK, anti-cleaved-caspase-3, cleaved-caspase-9, anti-Bax, anti- Bcl-2, anti-cytochrome c, and anti-actin antibodies were purchased from Santa Cruz Biotechnology (Santa Cruz, CA, USA). Goat anti-rabbit and anti-mouse IgG-HRP were purchased from Beyotime Institute of Biotechnology. (Beyotime Institute of Biotechnology, Shanghai, China).

All procedures involving animals were first approved by the Institutional Animal Care and Use Committee at Ji Lin Medical College. Sixty adult male Wistar rats (200 $\pm 20 \mathrm{~g})$ were purchased from the Experimental Animal Holding of Jilin University. The animal certification number was SCXK2008-0005. The animals were housed in standard polypropylene cages and maintained under conditions of controlled room temperature and humidity with $12 \mathrm{~h}$ (light)-12 h (dark) cycle. The rats were randomly distributed in 5 groups: the control group, 50, 100, 150 and $200 \mathrm{~mW} / \mathrm{cm}^{2}$ radiation injury group.

\section{Experimental method}

Rats were placed in the organic glass box, stamped. Then, rats were treated with microwave radiation at doses of $50,100,150$ and $200 \mathrm{~mW} / \mathrm{cm}^{2}$ for $6 \mathrm{~min}$ by a 2450 MHz microwave radiation source (MY8C-1) (Huiyan Systems Engineering, Nanjing, China). Non-treated rats were used as the control. The animals were maintained in $20 \pm 0.5^{\circ} \mathrm{C}$ temperature and $40-50 \%$ humidity during the experiment. After $6 \mathrm{~h}$ of 
microwave treatment, blood was collected from abdominal aorta and centrifuged $3,000 \times \mathrm{g} 4{ }^{\circ} \mathrm{C}$ for $10 \mathrm{~min}$. Heart were excised and cleaned and then immediately used for the next study. All experiments were performed in triplicate.

\section{Myocardial zymogram}

Blood was sampled from the abdominal aorta and serum was obtained by centrifugation at $3,000 \times \mathrm{g} 4{ }^{\circ} \mathrm{C}$ for $10 \mathrm{~min}$. The activity levels of serum creatine kinase $(\mathrm{CK})$, lactate dehydrogenase (LDH) and aspartate aminotransferase (AST) were determined using diagnostic kits (Jiancheng Bioengineering Institute, Nanjing, China) according to the manufacturer's instructions to assess the injury of myocardial.

\section{Estimation of cardiac troponin I}

The levels of cardiac troponin I (cTnI) in serum were estimated using standard kit by enzyme linked immunosorbent assay (Jiancheng Bioengineering Institute, Nanjing, China).

\section{Antioxidant assays}

Antioxidant enzymes such as SOD activities, MDA and GSH levels were determined in the heart. Cardiac tissue homogenates were prepared by homogenizing the tissues in a $0.1 \mathrm{M}$ phosphate buffer $\mathrm{pH}$ 7.4. The homogenate was then centrifuged at 3,000 $\mathrm{x}$ g $4{ }^{\circ} \mathrm{C}$ for $10 \mathrm{~min}$. The supernatant was collected and centrifuged again at $1000 \mathrm{~g}, 4^{\circ} \mathrm{C}$ for $30 \mathrm{~min}$. The final supernatant was then analyzed for estimation of SOD activities, MDA and GSH levels using diagnostic kits (Jiancheng Bioengineering Institute, Nanjing, China) according to assess the injury of myocardial.

\section{Measurement of the Mitochondrial Respiratory Chain Complexes Activities}


Myocardial mitochondria were isolated using a high-speed centrifugation by sucrose gradient method modified from the protocol described by Song (Song et al. 2014). Mitochondria were isolated at $4^{\circ} \mathrm{C}$ and mitochondrial protein concentration was routinely quantified with a Bradford assay using bovine serum albumin as a standard. Mitochondrial Respiratory Chain Complexes I, II, III, and IV were determined using diagnostic kits (Genmed Scientifics Inc, U.S.A).

\section{Determination of myocardial ATP activity levels}

Myocardial tissue was homogenized with $25 \mathrm{mM}$ Tris-HCl, $150 \mathrm{mM} \mathrm{NaCl}, 1 \% \mathrm{NP}-40$, $1 \%$ sodium deoxycholate, and $0.1 \%$ SDS. The homogenized tissue was centrifuged at $10,000 \times \mathrm{g}$ for $30 \mathrm{~min}$ at $4^{\circ} \mathrm{C}$ and the supernatant was used for ATP assessment. Myocardial ATP levels were assessed with ATP diagnostic kits (Genmed Scientifics, Inc., Wilmington, Delaware). ATP level was measured relative to ATP standards provided by the manufacturer.

\section{Detection apoptosis of myocardial cell}

Fresh heart tissues were placed onto a 120 mesh stainless steel net above a petri dish. The tissues were cut using ophthalmic scissors and gently rubbed with the scissors whilst rinsing with normal saline. The suspensions in the petri dish were filtered with a 300 mesh copper mesh filter to remove cell clumps. The cell suspension was collected and precipitated by centrifugation at $800 \times \mathrm{g}$ for $5 \mathrm{~min}$. The precipitate was collected and adjusted to $1 \times 10^{6}$ cells $/ \mathrm{ml}$. A total of $100 \mu \mathrm{l}$ cell suspension was taken and mixed $100 \mu \mathrm{l}$ MuseAnnexin V \& Dead Cell Reagents. Apoptosis was analyzed using Muse Cell Analyzer (Merck Millipore, Germany).

\section{Histopathological examination (HE)}


After sacrifice, the cardiac apex was rapidly dissected out and washed immediately with ice-cold normal saline and fixed in $10 \%$ buffered formalin. The fixed tissues were embedded in paraffin, sliced, coated, and stained with hematoxylin and eosin (H\&E). The sections were examined under light microscope and photomicrographs were taken.

\section{Transmission electron microscopy}

A small piece $\left(1 \mathrm{~mm}^{3}\right)$ of subendocardial myocardium was taken and fixed within $2.5 \%$ phosphate-buffered glutaraldehyde solution at $4{ }^{\circ} \mathrm{C}$. Post fixation was performed within 1\% phosphate-buffered osmium tetroxide for an hour. The samples were dehydrated by passing them through ethyl alcohol, embedded in Epon ${ }^{\circledR}$ 812, located by semithin sectioning, and sliced into ultrathin sections in a thickness of $60 \mathrm{~nm}$. The sections were dyed with uranium acetate and lead citrate, and observed by a JEM-1230 transmission electron microscope (Jeol; Tokyo, Japan).

\section{Western Blot Analysis}

After treatment, heart tissues were homogenized in lysis buffer containing $50 \mathrm{mM}$ Tris (pH 8.0), $10 \mathrm{mM}$ EDTA, $10 \mathrm{mM} \mathrm{Na}_{4} \mathrm{P}_{2} \mathrm{O}_{7}, 10 \mathrm{mM} \mathrm{NaF}, 1 \%$ Triton X-100, 125 $\mathrm{mM} \mathrm{NaCl}, 10 \mathrm{mM} \mathrm{Na} \mathrm{VO}_{4}$, and $1 \mu \mathrm{g} / \mathrm{ml}$ each of aprotinin and leupeptin. After centrifugation at $12,000 \times 1 \mathrm{~g}$ for $10 \mathrm{~min}$ at $4^{\circ} \mathrm{C}$, protein content was estimated according to Bio-Rad protein assay and $50 \mu \mathrm{g}$ protein/lane were loaded on to $12 \%$ polyacrylamide SDS gel. The separated proteins were then transferred elec-trophoretically to nitrocellulose paper and soaked in transfer buffer $(25 \mathrm{mmol} / \mathrm{L}$ Tris, $192 \mathrm{mmol} / \mathrm{L}$ glycine) and 20\% methanol v/v. Non-specific binding was blocked by incubation of the blots in 5\% no-fat dry milk in TBS/0.1\% Tween $(25 \mathrm{mmol} / \mathrm{L}$ Tris, $150 \mathrm{mmol} / \mathrm{L} \mathrm{NaCl}, 0.1 \%$ Tween $\mathrm{v} / \mathrm{v}$ ) for $60 \mathrm{~min}$. After washing, the blots were incubated overnight at $4{ }^{\circ} \mathrm{C}$ with the different primary antibodies overnight. After a 30 min wash, the membranes were incubated with secondary antibody conjugated to 
horseradish peroxide forl $\mathrm{h}$ at room temperature. The membranes were then washed for $30 \mathrm{~min}$ and exposed to enhanced chemiluminescence reagents for $1 \mathrm{~min}$ and developed on film. The BioRad Laboratories Quantity One software (BioRad, USA) was used to quantify the blots.

\section{Statistics}

All results are presented as mean \pm SD. Statistical analysis of the data were performed with one-way analysis of variance (ANOVA) followed by Tukey's test. In all cases differences were considered at $P<0.05$. 


\section{Results}

Effect of microwave radiation on the serum levels of creatinine kinase (CK), lactate dehydrogenase (LDH), and aspartate transaminase (AST)

The serum levels of CK, LDH, and AST were examined $6 \mathrm{~h}$ after irradiation. As shown in Figure 1, 50-200 $\mathrm{mW} / \mathrm{cm}^{2}$ of microwave irradiation led to dose-dependent increases in serum levels of CK, LDH, and AST. At doses of $100 \mathrm{~mW} / \mathrm{cm}^{2}, 150$ $\mathrm{mW} / \mathrm{cm}^{2}$ and $200 \mathrm{~mW} / \mathrm{cm}^{2}$, the CK activity was $712.12 \pm 72.75 \mathrm{U} / \mathrm{L}, 829.18 \pm 69.28$ $\mathrm{U} / \mathrm{L}$, and 1012.25 $\pm 120.13 \mathrm{U} / \mathrm{L}(P<0.01)$ respectively, indicating considerable increase compared with the control group $(485.45 \pm 95 \mathrm{U} / \mathrm{L})$. LDH activity was also significantly increased at $759.33 \pm 100.3 \mathrm{U} / \mathrm{L}, 929.46 \pm 56.1 \mathrm{U} / \mathrm{L}$, and $1124.66 \pm$ $58.92 \mathrm{U} / \mathrm{L}(P<0.01)$, respectively, compared with that of the control group $(579.79 \pm$ 113.12 U/L). Lastly, AST activity was $123.15 \pm 8.9 \mathrm{U} / \mathrm{L}, 189.76 \pm 7.92 \mathrm{U} / \mathrm{L}$, and $200.15 \pm 15.36 \mathrm{U} / \mathrm{L}(P<0.01)$, respectively, whereas the control group was $89.16 \pm$ $12.12 \mathrm{U} / \mathrm{L}$.

\section{Effect of microwave radiation on cTnI}

Serum levels of cTnI can be used as an indicator of myocardial damage. Microwave radiation treatment induced marked increase in $\mathrm{cTnI}$ content compared with the control group. At doses of $100 \mathrm{~mW} / \mathrm{cm}^{2}, 150 \mathrm{~mW} / \mathrm{cm}^{2}$ and $200 \mathrm{~mW} / \mathrm{cm}^{2}$, the $\mathrm{cTnI}$ content was $1.72 \pm 0.17 \mathrm{ng} / \mathrm{ml}, 2.89 \pm 0.42 \mathrm{ng} / \mathrm{ml}$ and $4.24 \pm 0.34 \mathrm{ng} / \mathrm{ml}(P<0.01)$ respectively, showing considerable increase compared with that of the control group (Fig. 2). These results clearly indicated that microwave radiation could cause myocardial injury.

Effect of microwave radiation on the levels of superoxide dismutase (SOD), malondialdehyde content (MDA), and glutathione (GSH) 
MDA is regarded as a major marker of lipid peroxidation in tissues, whereas SOD and GSH are two important enzymes in the antioxidant defense system. After exposure to microwave radiation, MDA content, SOD and GSH activity in myocardial cells were measured (Fig. 3). In the $100 \mathrm{~mW} / \mathrm{cm}^{2}, 150 \mathrm{~mW} / \mathrm{cm}^{2}$ and $200 \mathrm{~mW} / \mathrm{cm}^{2}$ microwave groups, SOD activity was $80.28 \pm 8.21 \mu / \mathrm{mg}$ prot, $79.15 \pm 6.89 \mu / \mathrm{mg}$ prot, and 68.34 $\pm 7.56 \mu / \mathrm{mg} \operatorname{prot}(P<0.01)$, respectively, indicating substantial decrease compared with the control group $(102.45 \pm 10.24 \mu / \mathrm{mg}$ prot $)$. GSH activity was $5.85 \pm 0.33 \mu / \mathrm{mg}$ prot, $4.02 \pm 0.29 \mu / \mathrm{mg}$ prot, and $3.87 \pm 0.24 \mu / \mathrm{mg}$ prot $(P<0.01)$ compared with that in the control group $(102.45 \pm 6.96 \mu / \mathrm{mg}$ prot $)$. Moreover, MDA activity was $10.15 \pm$ $1.25 \mathrm{nmol} / \mathrm{g}$ prot, $12.26 \pm 0.99 \mathrm{nmol} / \mathrm{g}$ prot, and $14.59 \pm 1.45 \mathrm{nmol} / \mathrm{g}$ prot $(P<0.01)$, all of which were higher than that of the control group $(7.56 \pm 0.62 \mathrm{nmol} / \mathrm{g}$ prot $)$. These data indicated that microwave radiation could change the activity of antioxidative stress enzymes.

\section{Effects of microwave radiation on mitochondrial complex activity}

To evaluate the effect of microwave radiation on mitochondrial function, we measured enzyme activities of complexes I-IV. After exposure to microwaves at doses of $50 \mathrm{~mW} / \mathrm{cm}^{2}, 100 \mathrm{~mW} / \mathrm{cm}^{2}, 150 \mathrm{~mW} / \mathrm{cm}^{2}$ or $200 \mathrm{~mW} / \mathrm{cm}^{2}$ for $6 \mathrm{~min}$, the mitochondria were isolated to determine the activity of complexes I-IV. As shown in Figure 4, enzyme activity in all four complexes decreased inversely according to the increased doses of microwave radiation. In the $100 \mathrm{~mW} / \mathrm{cm}^{2}, 150 \mathrm{~mW} / \mathrm{cm}^{2}$, and 200 $\mathrm{mW} / \mathrm{cm}^{2}$ microwave group, the activity of complexes I-IV decreased dramatically $(P$ $<0.01)$. We could therefore speculate that increased doses of microwave radiation negatively regulate mitochondrial function.

\section{Effect of microwave radiation on the levels of myocardial ATP}

The heart is highly dependent on continuous ATP delivery from mitochondria in order to maintain cardiac function. In the current study, myocardial ATP levels were 
assessed after exposure to microwave radiation. The results showed that ATP content in the myocardial tissue decreased after microwave irradiation (Fig. 5). In the 100 $\mathrm{mW} / \mathrm{cm}^{2}, 150 \mathrm{~mW} / \mathrm{cm}^{2}$ or $200 \mathrm{~mW} / \mathrm{cm}^{2}$ microwave group, ATP activity was $0.411 \pm$ $0.03 \mathrm{umol} / \mathrm{g}$ prot, $0.326 \pm 0.014 \mathrm{umol} / \mathrm{g}$ prot and $0.211 \pm 0.059 \mathrm{umol} / \mathrm{g}$ prot $(P<0.01)$, respectively, showing significant decrease compared with that in the control group $(0.479 \pm 0.016 \mathrm{umol} / \mathrm{g}$ prot). These data indicated that microwave doses of 100 $\mathrm{mW} / \mathrm{cm}^{2}, 150 \mathrm{~mW} / \mathrm{cm}^{2}$ and $200 \mathrm{~mW} / \mathrm{cm}^{2}$ could induce significant myocardial injury. Therefore, doses of $100 \mathrm{~mW} / \mathrm{cm}^{2}, 150 \mathrm{~mW} / \mathrm{cm}^{2}$, and $200 \mathrm{~mW} / \mathrm{cm}^{2}$ were used in all subsequent experiments.

\section{Effects of microwave radiation on myocardial cells apoptosis}

To determine the effect of microwave radiation on myocardial cell apoptosis, we stained the cells with Muse Annexin V \& Dead Cell Reagent (EMD Millipore, Billerica, Massachusetts). A Muse Cell Analyzer was used to quantify fluorescent cells. A number of cells showed enhanced early apoptosis with increasing doses of microwave radiation (Fig. 6). The percentages of apoptosis detected by Annexin V-FITC were $3.05 \pm 0.32 \%, 9.68 \pm 0.89 \%, 12.34 \pm 0.48 \%$ and $17.10 \pm 0.92 \%$, with microwave doses of $0 \mathrm{~mW} / \mathrm{cm}^{2}, 100 \mathrm{~mW} / \mathrm{cm}^{2}, 150 \mathrm{~mW} / \mathrm{cm}^{2}$, and $200 \mathrm{~mW} / \mathrm{cm}^{2}$, respectively. In general, the number of apoptotic myocardial cells significantly increased with microwave radiation treatment in a dose-dependent manner.

\section{Morphological analysis}

HE staining showed that myocardial cells of rats in the control group were cylindrical, with parallel muscle fibers and clear horizontal stripes. In contrast, myocardial cells of rats in the radiation damage groups showed mild pitting edema with disordered muscle fibers and unclear horizontal stripes. Damage became more severe with increasing microwave radiation intensity. Myocardial fibers in the $200 \mathrm{~mW} / \mathrm{cm}^{2}$ microwave radiation group showed water degeneration and transparency with diffuse 
nuclear pyknosis and hyperchromatism. In some cases, myocardial fibers were obviously broken. The degree of myocardial cell damage was dose-dependent (Fig.7 I ). Electron micrographs demonstrated that myofilaments in the myocardial cells of rats in the control group were arranged tightly and regularly with clear horizontal stripes. Abundant mitochondria and glycogen granules were also observed. Mitochondria were arranged regularly in circular, oval, or long rod forms. Furthermore, mitochondrial membranes were complete, and crests were clearly visible. In contrast, the mitochondria and myofilaments of myocardial cells of rats in the microwave irradiated groups were arranged loosely. Mitochondrion numbers also decreased in an abnormal pattern. Some mitochondria were dissolved and appeared cavitated with bloated cytoplasm. Integrity of the inner and outer membranes was significantly broken. Myocardial cell damage clearly became more severe with increasing microwave radiation intensity (Fig. 7 II).

\section{Effects of microwave radiation on protein expression}

Members of the Bcl-2 family of proteins, such as Bcl-2 and Bax are critical regulators of the apoptotic pathway. Bcl-2 protects against multiple signals that leads to cell apoptosis, whereas Bax induces apoptosis. The ratio of $\mathrm{Bax} / \mathrm{Bcl}-2$ is crucial for activation of the mitochondrial apoptotic pathway. Our data demonstrated that, after microwave irradiation, expression of Bcl-2 decreased, whereas that of Bax increased. Thus, the ratio of $\mathrm{Bax} / \mathrm{Bcl}-2$ increased upon further exposure to microwave radiation. Next, we investigated the protein levels of CytoC, cleaved caspase-9, and cleaved caspase-3. Results of Western blot showed that expression of cleaved caspase-3, cleaved caspase-9, and Cyto C increased after microwave treatment (Fig. 8). These results indicated that microwave exposure could lead to myocardial cell apoptosis through a mitochondria-independent pathway.

The mitogen-activated protein kinase (MAPK) cascades (e.g., ERK and JNK) have been identified as upstream signaling mechanisms responsible for regulating oxidative 
stress and cell apoptosis. To evaluate whether microwave radiation affected the signaling pathways associated with activation of MAPK signaling cascades, we examined changes in the activation of the signaling proteins p-ERK, ERK, p-JNK, and JNK. As shown in Figure 9, treatment with sequentially higher microwave doses dramatically increased the levels of p-ERK and p-JNK. 


\section{Discussion}

The heart consumes large amounts of energy and oxygen in an animal. ATP is the only form of energy that can be directly used by myocardial tissues, and these tissues must continue to synthesize ATP to maintain normal function and cell vitality (Cong et al. 2014; Doenst et al. 2013; Sinha et al. 2013). A growing body of evidence shows that cardiac energy metabolism disorders initiate myocardial cell injury and likely cause and promote impairments of cardiac function. Several studies have demonstrated that microwave radiation damages the heart, but further experiments are needed to verify their conclusions (Avci et al. 2012; Li et al. 2014). In addition, the mechanism of microwave radiation damage and effective countermeasures against such damage are still poorly understood. In this study, the damage caused by $2450 \mathrm{MHz}$ microwave irradiation of the heart and the mechanism underlying such damage were investigated in rats. The results obtained herein have significant theoretical and practical implications.

Various enzymes are released from myocardial cells into the blood upon myocardial damage, and changes in serum enzymology can be assessed easily (Arslan et al. 2013; Dey et al. 2013). Indeed, the myocardial enzyme spectrum in serum is an important indicator of the extent of myocardial damage. The integrity of cardiac tissue is important in drug biotransformation and metabolism, and is highly associated with serum levels of CK, LDH, and AST. When oxidative damage occurs, high activity of these enzymes can be detected in the blood. The present study showed that rats treated with microwaves at doses of $50 \mathrm{~mW} / \mathrm{cm}^{2}, 100 \mathrm{~mW} / \mathrm{cm}^{2}, 150 \mathrm{~mW} / \mathrm{cm}^{2}$, and 200 $\mathrm{mW} / \mathrm{cm}^{2}$ for $6 \mathrm{~min}$ had marked increases in serum levels of CK, LDH, and AST. Serum levels of cTnI can be used as an indicator of myocardial damage. After microwave irradiation, the $\mathrm{cTnI}$ content was found to have increased in the current study. These results indicated that microwaves could cause myocardial injury. Oxidative damage can have devastating effects on cells. Exogenous oxidants can cause accumulation of intracellular reactive oxygen species (ROS), which are also generated in the aerobic metabolic processes of cells (Dawson et al. 2012; Khairova et 
al. 2012; Rains and Jain 2011). Because of their high biological activity, ROS easily reacts with biological macromolecules and directly damages or promotes destruction of biological structures through a series of peroxide chain reactions (Yu et al. 2013). Cells can generally maintain normal functions when oxidation and anti-oxidation are in equilibrium. When this balance is compromised, cellular functions may be disrupted. Our study showed that SOD levels and GSH activity in myocardial cells of irradiated rats were lower than those in the control group. Moreover, MDA contents in the irradiated groups were significantly higher compared to the control group. These results indicated that lipid peroxidation with excessive SOD and GSH consumption gradually accelerated in organisms after microwave irradiation. The increase in MDA activity might be induced via generation of oxygen free radicals promoted by cell damage. Thus, oxidative stress in myocardial cells caused by microwave irradiation could lead to imbalance between the body's oxidation and anti-oxidation systems. Each cell mitochondria are its major energy source. As the source and target of reactive oxygen, mitochondria may be pathologically altered under free radical attack (Habersetzer et al. 2013; Wallace 2012). To evaluate the effect of microwave irradiation on mitochondrial function, we measured the enzyme activities of complexes I-IV. After treatment with microwaves at doses of $50 \mathrm{~mW} / \mathrm{cm}^{2}, 100$ $\mathrm{mW} / \mathrm{cm}^{2}, 150 \mathrm{~mW} / \mathrm{cm}^{2}$, and $200 \mathrm{~mW} / \mathrm{cm}^{2}$, the enzyme activities of complexes I-IV decreased as the dose of microwave radiation increased. HE staining and electron microscopy showed that the mitochondria and myofilaments of rats in the microwave radiation groups were arranged loosely with fuzzy horizontal stripes and unclear bright and dark bands. Some myofilaments were also dissolved and broken. Mitochondria in cells in these groups appeared highly abnormal. The majority of mitochondria were dissolved, cavitated, and/or showed significantly bloated cytoplasm. This indicated that cardiac energy metabolism of rats became abnormal and myocardial cells were damaged by microwave irradiation. Thus, our results indicated that microwave radiation had negative impact on mitochondrial function in a dose-dependent manner.

Mitochondria actively regulate cell death, with the final phenotype of demise being 
determined by the metabolic and energy status of the cell (Hänsch and Zimmermann 1993). A mitochondrion is not only an energy-producing organelle but also an important apoptosis regulator. Bcl-2 and Bax levels are inversely related to fluctuation of apoptosis; these proteins adjust release of Cyto $\mathrm{C}$, the critical trigger of apoptotic signaling cascade (Martinou and Youle 2011). Activated Bax induces the intrinsic apoptotic signaling pathway by using the mitochondrial intermembrane space to generate apoptosis by releasing Cyto $\mathrm{C}$ into the cytosol. However, Bcl-2 blocks the release of Cyto $\mathrm{C}$ from the mitochondria. In the cytosol, Cyto C activates caspase-9, which then activates effector caspases, including caspase-3 (D'Amelio et al. 2011; Hu et al.2014; Qin et al.2013). In the present study, microwave treatment downregulated the expression of Bcl-2 and increased the expression of Bax in myocardial cells of rats. The $\mathrm{Bax} / \mathrm{Bcl}-2$ ratio increased as microwave irradiation became stronger. This suggested that microwave treatment facilitated myocardial cell apoptosis. We further determined that the protein levels of Cyto C, cleaved caspase-9, and cleaved caspase-3 had all increased significantly after microwave treatment.

Oxidative stress is the result of imbalance in pro-oxidant/antioxidant homeostasis. It is also well known that JNK is an important regulator of cell apoptosis and survival in response to oxidative stress. JNKs are involved in cell apoptosis by participating in the cellular response to stress, while cell survival is usually regulated by ERK with a short period of activation (Justin and Jain 2011). Microwave radiation could lead to imbalance between the oxidation and anti-oxidation systems in myocardial cells and induce apoptosis. To further understand changes in the apoptotic pathways, the levels of ERK and JNK were determined. The ERK and JNK signaling pathways are involved in a wide variety of cellular functions, including growth, differentiation, inflammation, and apoptosis, and are a ROS downstream gateway to apoptosis. (Bavaria et al. 2014; Dhanasekaran 2013; Song et al. 2013). In the present study, we observed that microwave irradiation significantly altered oxidative stress balance and increased the levels of phosphorylated ERK and JNK, which had pro-apoptotic effects on myocardial cells. 


\section{Conclusions}

In conclusion, microwave irradiation induces dramatic oxidative damage to rat myocardial cells. Microwave irradiation causes oxidative stress imbalance, mitochondrial dysfunction, and myocardial cell apoptosis. Myocardial cell damage from microwaves may be related to increase of Cyto C, activation of cleaved caspase-9 and cleaved caspase-3, upregulation of Bax expression, and/or downregulation of Bcl-2 protein level. Furthermore, microwave irradiation significantly activates the ERK and JNK signaling pathways through oxidative stress in myocardial cells. The current study provides mechanistic insights into the effect of $2450 \mathrm{MHz}$ microwave irradiation on rat myocardial cells. Nevertheless, further studies are still needed to explore more about these mechanisms. 


\section{Conflicts of Interest}

The authors declare no conflicts of interest. 


\section{Acknowledgments}

This work was supported by Project Agreement for Science \&Technology Development, Jilin Province (No. 20140204002YY), Excellent Youth Talents Training programs of Jilin City (No.2015642800) National Natural Science Foundation of China (NO. 81273421, No.81301450 and 81202953) and the national science and technology major projects (NO. 2012ZX09103-301-003), Research program supported by Health and Family Planning Commission of Jilin Province (2013Q030). 


\section{Reference}

Arslan, F., Lai, R.C., Smeets, M.B., Akeroyd, L., Choo, A., Aguor, E.N., et al. 2013. Mesenchymal stem cell-derived exosomes increase ATP levels, decrease oxidative stress and activate PI3K/Akt pathway to enhance myocardial viability and prevent adverse remodeling after myocardial ischemia/reperfusion injury. Stem Cell Res. 10(3):301-312. doi: 10.1016/j.scr.2013.01.002. PMID: 23399448.

Avci, B., Akar, A., Bilgici, B., and Tunçel, Ö.K. 2012. Oxidative stress induced by 1.8 $\mathrm{GHz}$ radio frequency electromagnetic radiation and effects of garlic extract in rats. Int. J. Radiat. Biol. 88(11):799-805. doi: 10.3109/09553002.2012.711504. PMID: 22788526.

Bavaria, M.N., Jin, S., Ray, R.M., and Johnson, L.R. 2014. The mechanism by which MEK/ERK regulates JNK and p38 activity in polyamine depleted IEC-6 cells during apoptosis. Apoptosis. 19(3):467-79. doi: 10.1007/s10495-013-0944-1. MID: 24253595.

Cong, W., Zhao, T., Zhu, Z., Huang, B., Ma, W., Wang, Y., et al 2014. Metallothionein prevents cardiac pathological changes in diabetes by modulating nitration and inactivation of cardiac ATP synthase. J. Nutr. Biochem. 25(4):463-74. doi: 10.1016/j.jnutbio.2013.12.007. PMID: 24629910.

D'Amelio, M., Cavallucci, V., Middei, S., Marchetti, C., Pacioni, S., Ferri, A.,et al. 2011. Caspase-3 triggers early synaptic dysfunction in a mouse model of Alzheimer's disease. Nat. Neurosci. 14(1):69-76. doi: 10.1038/nn.2709. PMID: 21151119.

Dasdag, S., Akdag, M.Z., Ulukaya, E., Uzunlar, A.K., and Ocak, A.R. 2009. Effect of mobile phone exposure on apoptotic glial cells and status of oxidative stress in rat brain. Electromagn. Biol. Med. 28(4):342-54. doi:

10.3109/15368370903206556. PMID: 20017625.

Dawson, M. A., and Kouzarides, T. 2012. Cancer epigenetics: from mechanism to therapy. Cell. 150(1):12-27. doi: 10.1016/j.cell.2012.06.013. PMID: 22770212.

Dey, D., Han, L., Bauer, M., Sanada, F., Oikonomopoulos, A., Hosoda, T., et al. 2013. 
Dissecting the molecular relationship among various cardiogenic progenitor cells. Circ. Res. 112(9):1253-62. doi: 10.1161/CIRCRESAHA.112.300779. PMID: 23463815 .

Dhanasekaran, D. N. 2013. JNK Signaling Network and Cancer. Genes. Cancer 4(9-10):332-333. doi: 10.1177/1947601913507949

Doenst, T., Nguyen, T. D., and Abel, E. D. 2013. Cardiac metabolism in heart failure implications beyond ATP production. Circ. Res. 113(6):709-24. doi:

10.1161/CIRCRESAHA.113.300376. PMID: 23989714.

Gupta, J. P. 2014. Microwave radiation hazards from radars and other high power microwave generators. Defence. Sci. J. 38 (3): 287-292. DOI: $10.14429 / \mathrm{dsj} .38 .5850$.

Habersetzer, J., Ziani, W., Larrieu, I., Stines-Chaumeil, C., Giraud, M.F., Brèthes, D., et al. 2013. ATP synthase oligomerization: from the enzyme models to the mitochondrial morphology. Int. J. Biochem. Cell. Biol. 45(1):99-105. doi: 10.1016/j.biocel.2012.05.017. PMID: 22664329.

Hänsch, T. W., and Zimmermann, C. 1993. Laser spectroscopy of hydrogen and antihydrogen. Hyperfine. Interact. 76(1): 47-57.

Hu, Q., Wu, D., Chen, W., Yan, Z., Yan, C., He, T. et al. 2014. Molecular determinants of caspase-9 activation by the Apaf-1 apoptosome. Proc. Natl. Acad. Sci. U.S.A. 111(46):16254-16261. doi: 10.1073/pnas.1418000111. PMID: 25313070.

Jauchem, J.R. 1995. Alleged health effects of electromagnetic fields: the misconceptions continue. J. Micrwvave, Power. Ee. 30(3):165-177. PMID: 7472919.

Jauchem, J.R., and Frei, M.R. 1997. Body heating induced by subreson ant (350MHz) microwave irradiation: cardiovascular and respiratory responses in anesthetized rats. Bioelectromagnetics. 18(4): 225-338. PMID: 9140664.

Jing, J., Yuhua, Z., Xiaoqian, Y., Rongping, J., Dongmei, G., Xi, C. 2012. The influence of microwave radiation from cellular phone on fetal rat brain. Electromagn. Biol. Med. 31(1):57-66. doi: 10.3109/15368378.2011.624652. PMID: 22268709. 
Khairova, R., Pawar, R., Salvadore, G., Juruena, M.F., de, Sousa, R.T., Soeiro-de-Souza, M.G., et al.2012. Effects of lithium on oxidative stress parameters in healthy subjects. Mol. Med. Rep. 5(3):680-2. doi:

10.3892/mmr.2011.732. PMID: 22200861.

Li. Y., Qu, X., Wang, X., Liu, M., Wang, C., Lv, Z., Li, W., et al. 2014. Microwave Radiation Injures Microvasculature Through Inducing Endoplasmic Reticulum Stress. Microcirculation. 21(6): 490-498. doi: 10.1111/micc.12122. PMID: 24635541.

Martinou, J.C., and Youle, R. J. 2011. Mitochondria in apoptosis: Bcl-2 family members and mitochondrial dynamics. Dev. Cell. 21(1):92-101. doi: 10.1016/j.devcel.2011.06.017. PMID: 21763611.

Qin, S., Yang, C., Wang, X., Xu, C., Li, S., Zhang, B., et al. 2013. Overexpression of Smac promotes cisplatin-induced apoptosis by activating caspase- 3 and caspase-9 in lung cancer A549 cells. Cancer. Biother. 28(2):177-182. doi: 10.1089/cbr.2012.1261. PMID: 23252748.

Rains, J.L., and Jain, S.K. 2011. Oxidative stress, insulin signaling, and diabetes. Free. Free. Radic. Bio. Med. 50 (5): 567-575. doi: 10.1016/j. freeradbiomed. 2010. 12. 006. PMID: 21163346.

Shahin, S., Singh, V.P., Shukla, R.K., Dhawan, A., Gangwar, R.K., Singh, S.P., et al. 2013. 2.45 GHz microwave irradiation-induced oxidative stress affects implantation or pregnancy in mice, Mus musculus. Appl. Biochem. Biotechnol. 169(5):1727-51. doi: 10.1007/s12010-012-0079-9. PMID: 23334843.

Siddiqi, N., Singh, S., Beadle, R., Dawson, D., and Frenneaux, M. 2013. Cardiac metabolism in hypertrophy and heart failure: implications for therapy. Heart. Fail. Rev. 18(5):595-606. doi: 10.1007/s10741-012-9359-2. PMID: 23124940.

Sinha, K., Das, J., Pal, P.B., and Sil, P.C. 2013. Oxidative stress: the mitochondriadependent and mitochondria-independent pathways of apoptosis. Arch. Toxicol. 87(7):1157-1180. doi: 10.1007/s00204-013-1034-4. PMID: 23543009.

Song, L., Zhao, J., Zhang, X., Li, H., and Zhou, Y. 2013. Icariin induces osteoblast proliferation, differentiation and mineralization through estrogen 
receptor-mediated ERK and JNK signal activation. Eur. J. Pharmacol. 714(1-3):15-22. doi: 10.1016/j.ejphar.2013.05.039. PMID: 23764463.

Song, R., Zhu, S., Zhang, H., Li, X., and Wu, S. 2014. ATPase may play a critical role in disturbance of energy metabolism in congestive heart failure rats. Int. J. Clin. Exp. Med. 7(10): 3654-3658. PMID: 25419414.

Wallace, D. C. 2012. Mitochondria and cancer. Nat. Rev. Cancer. 12(10):685-98. doi: 10.1038/nrc3365. PMID: 23001348.

Yu, E., Calvert, P.A., Mercer, J.R., Harrison, J., Baker, L., Figg, N.L. et al. 2013. Mitochondrial DNA damage can promote atherosclerosis independently of reactive oxygen species through effects on smooth muscle cells and monocytes and correlates with higher-risk plaques in humans. Circulation. 128(7):702-12. doi: 10.1161/CIRCULATIONAHA.113.002271. PMID: 23841983.

Zhang, Q.J., Yang, C.L., Luo, L.H., Mu, H.L., Wang, R.Y., Du, P., et al. 2012. Effects of High Power Microwave Radiation on ATPase Activity and Oxidative Stress of Myocardium in Mice. Chinese Journal of Space Medicine \& Medical Engineering. 25(3): 176-179.

Zuo, H., Lin, T., Wang, D., Peng, R., Wang, S., Gao, Y., et al. 2014. Neural Cell Apoptosis Induced by Microwave Exposure Through Mitochondria-dependent Caspase-3 Pathway. Int. J. Med. Sci. 11(5):426-35. doi: 10.7150/ijms.6540. PMID: 24688304. 
Fig 1. Rats were treated with microwaves by the doses of $50 \mathrm{~mW} / \mathrm{cm}^{2}, 100 \mathrm{~mW} / \mathrm{cm}^{2}$, $150 \mathrm{~mW} / \mathrm{cm}^{2}$ or $200 \mathrm{~mW} / \mathrm{cm}^{2}$ for $6 \mathrm{~min}$. After $6 \mathrm{~h}$ of treatment, blood was collected from abdominal aorta. The serum levels of CK, LDH and AST were detected respectively. Data are the mean $\pm \mathrm{SD}, n=6 ; * P<0.05, * * P<0.01$ compared with the control group.

Fig. 2 Effects of microwaves on serum levels of cTnI in rat. Data are the mean $\pm \mathrm{SD}, n$ $=6 ; * * P<0.01$ compared with the control group.

Fig. 3 After $6 \mathrm{~h}$ of treatment, cardiac tissue homogenates were prepared to detect the effect of microwave radiation on oxidative stress parameters for superoxide dismutase (SOD), reduced glutathione (GSH), and malondialdehyde (MDA) enzyme activity. (I) Serum SOD activity. (II) Serum MDA content. (III) Serum GSH activity. Data are the mean $\pm \mathrm{SD}, n=6 ; * P<0.05, * * P<0.01$ compared with the control group.

Fig. 4 After $6 \mathrm{~h}$ of microwave treatment, myocardial mitochondria were isolated. Effect of microwave radiation on the activities of myocardial mitochondrial complex I, complex II, complexIII and complex IV activities were detected. Data are the mean \pm $\mathrm{SD}, n=6 ; * P<0.05, * * P<0.05$ compared with the control group.

Fig. 5 Effect of microwave radiation on the activities of myocardial ATP activity. Myocardial tissues were homogenized and centrifuged. The supernatant was used for ATP assessment. Data are the mean $\pm \mathrm{SD}, n=6 ; * P<0.05, * * P<0.01$ compared with the control group.

Fig. 6 The apoptosis rate of myocardial cells treated with microwaves, as determined using a Muse ${ }^{\mathrm{TM}}$ Annexin V \& Dead Cell reagent. ( I ) Muse ${ }^{\mathrm{TM}}$ Cell Analyzer analysis of annexin-V stained cells. A Control group. B,C and D was the group treated with microwave doses of $100 \mathrm{~mW} / \mathrm{cm}^{2}, 150 \mathrm{~mW} / \mathrm{cm}^{2}$ and $200 \mathrm{~mW} / \mathrm{cm}^{2}$. ( II ) Quantitative analysis of data from the lower right quadrant in (A). Data are the mean $\pm \mathrm{SD}, n=6$; 
** $P<0.01$ compared with the control group.

Fig. 7 Histological and ultrastrucural changes in the heart. ( I ) Myocardial cells morphological Analysis by HE staining (magnification, $400 \times$ ). After microwave irradiation, the myocardial tissues was fixed and stained with hematoxylin and eosin (H\&E). The morphological change was examined under light microscope. (II) The ultrastructure changes of heart tissue was analyzed by TEM (magnification, $1000 \times$ ). After microwave irradiation, the morphological ultrastructure change was examined under TEM. A Control group. B, C and D were the group treated with microwave doses of $100 \mathrm{~mW} / \mathrm{cm}^{2}, 150 \mathrm{~mW} / \mathrm{cm}^{2}$ and $200 \mathrm{~mW} / \mathrm{cm}^{2}$.

Fig. 8 Effects of microwave on apoptotic and antiapoptotic protein expression in myocardial cells. (A) Western blot for Bax, Bcl-2, cleaved caspase-3, cleaved caspase-9 and Cyt c protein expression. (B) Quantitation of the effects of microwave on the ratio of Bax/Bcl-2. (C) Quantitation of the effects of microwave on cleaved caspase-3 expression. (D) Quantitation of the effects of microwave on cleaved caspase-9 expression. (E) Quantitation of the effects of microwave on cleaved Cyt c expression. Values are the mean $\pm \mathrm{SD}, n=5$. ${ }^{* *} P<0.01$ compared with the control group.

Fig. 9 Representative blots showing the effects of microwave on phosphorylated and total ERK expression. (A) Western blot for phosphorylated and total ERK and JNK expression. (B) Quantitation of effect of microwave on phosphorylated and total ERK protein expression. (C) Quantitation of effect of microwave on phosphorylated and total JNK protein expression Values are the mean $\pm \mathrm{SD}, n=5$. ${ }^{* *} P<0.01$ compared with the control group. 


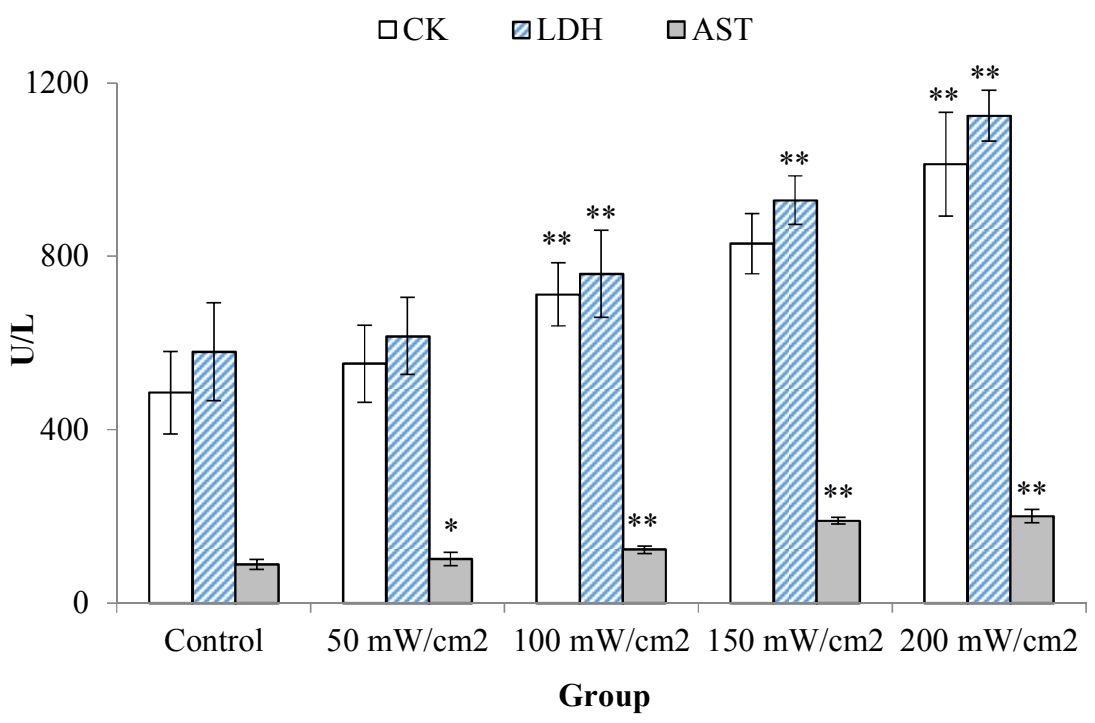

Fig. 1 


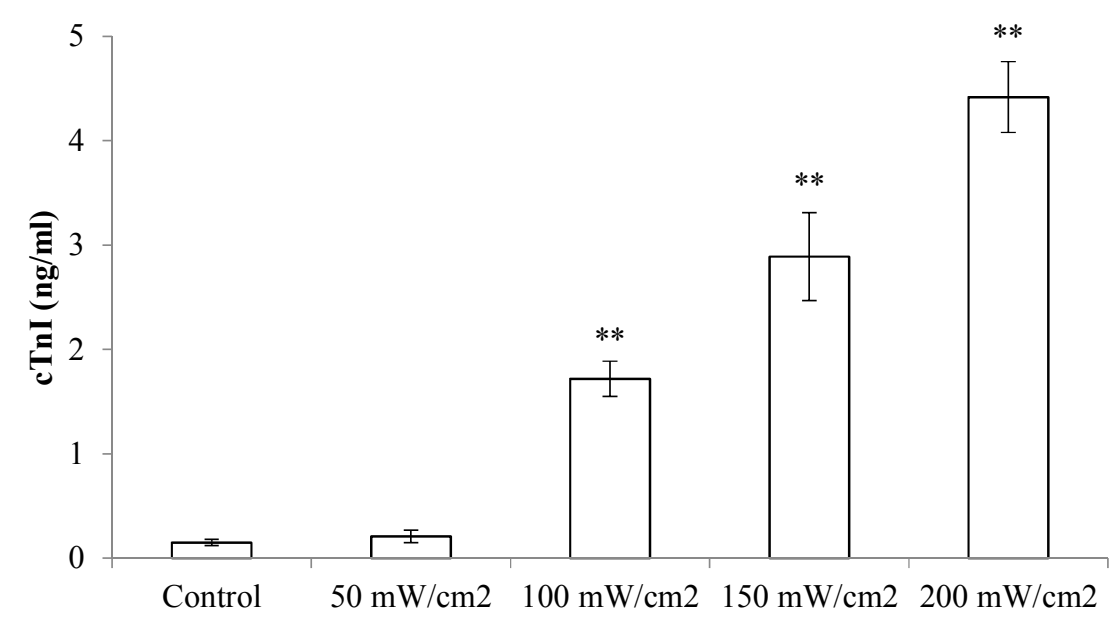

Fig. 2 

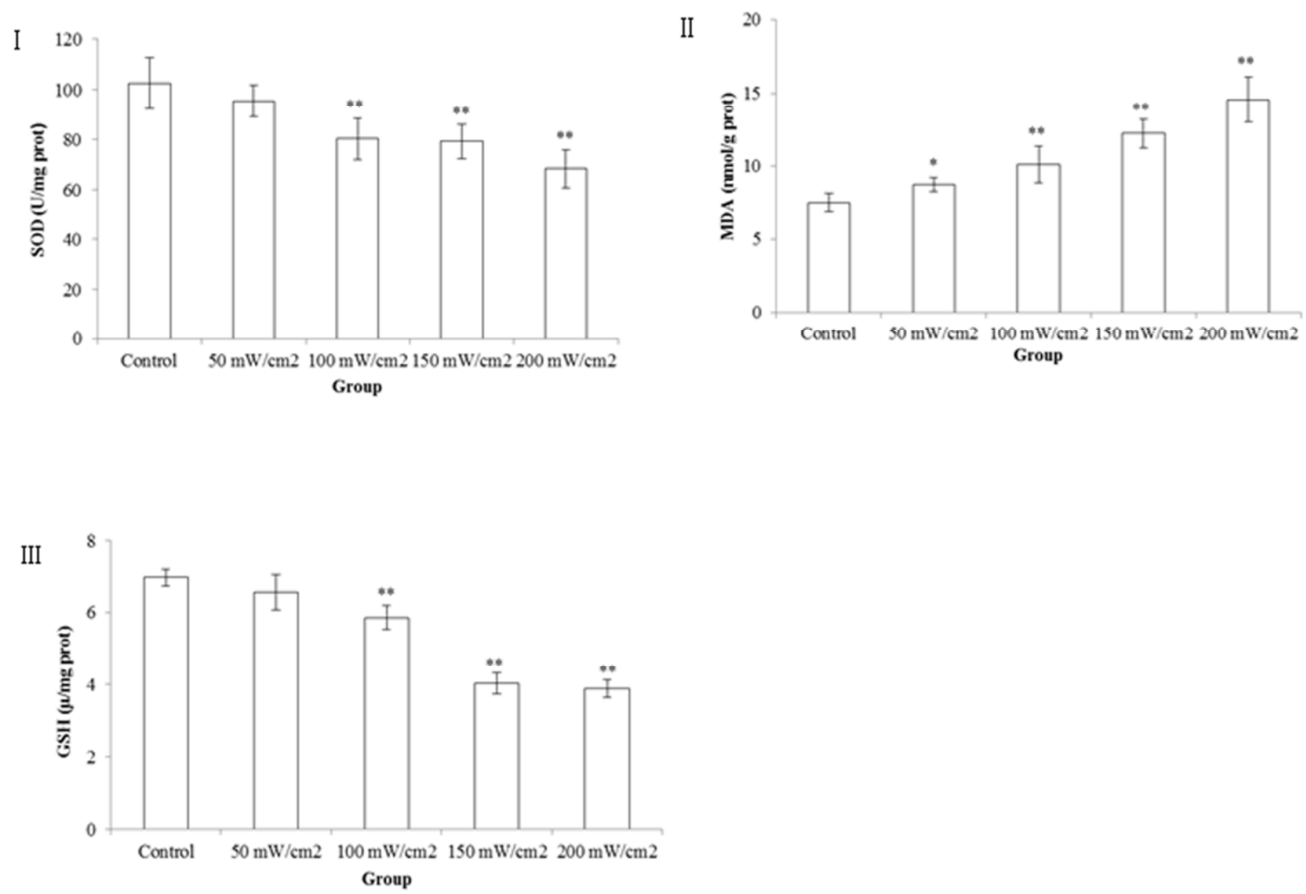

Fig. 3 


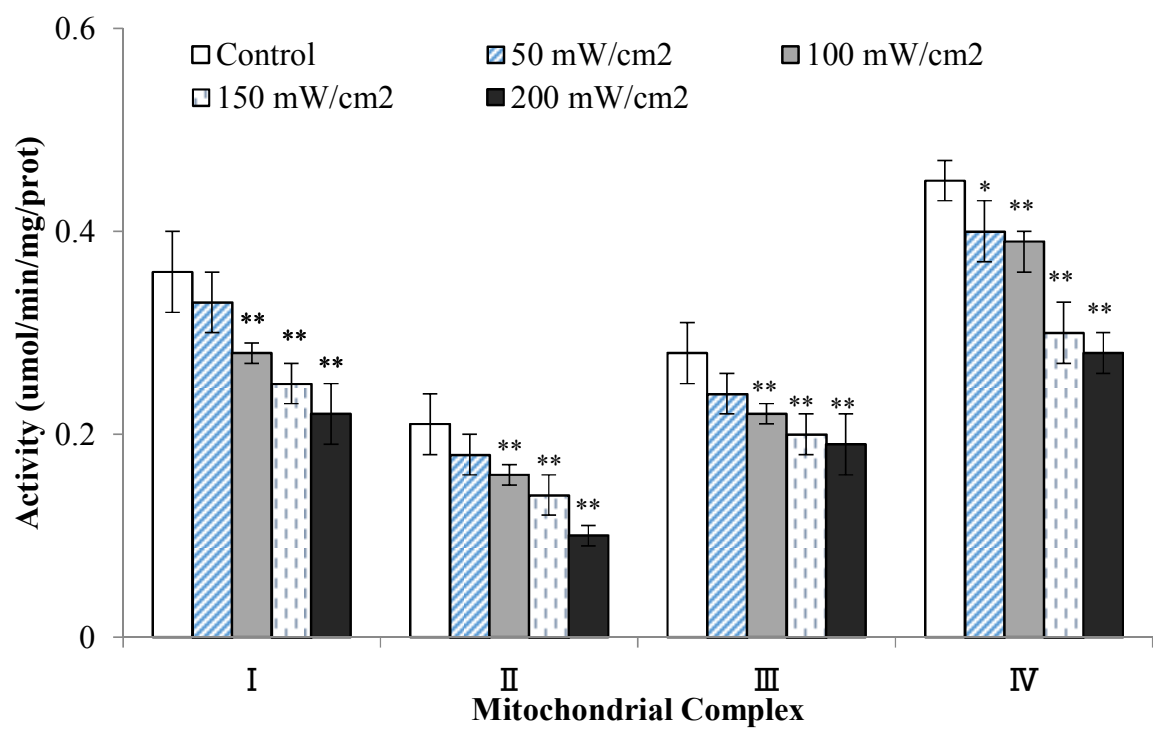

Fig. 4 


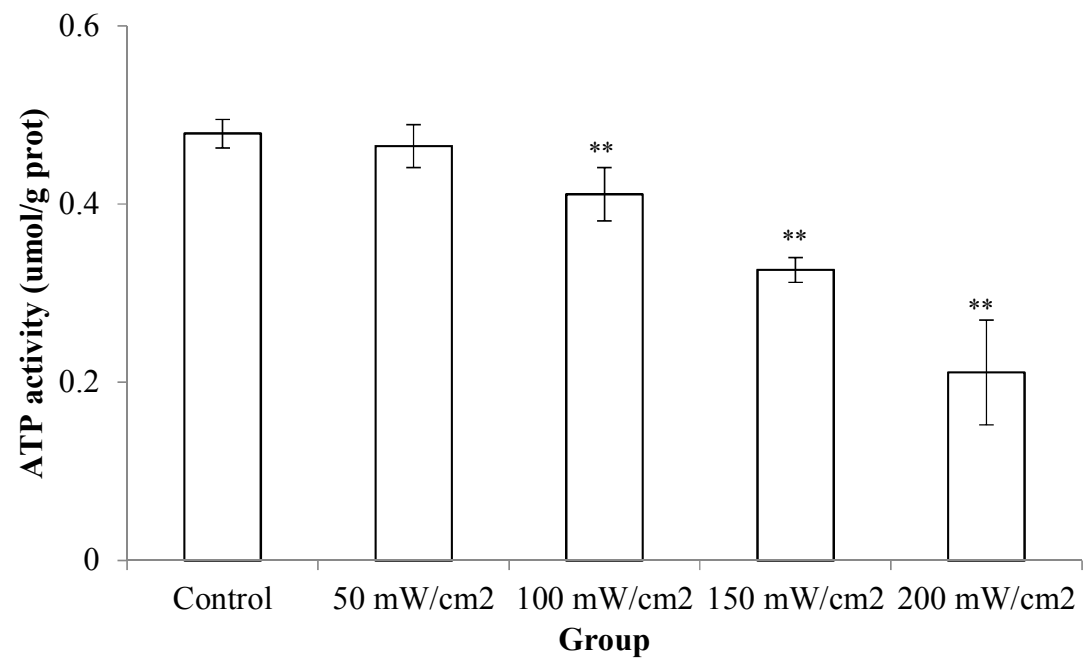

Fig. 5 

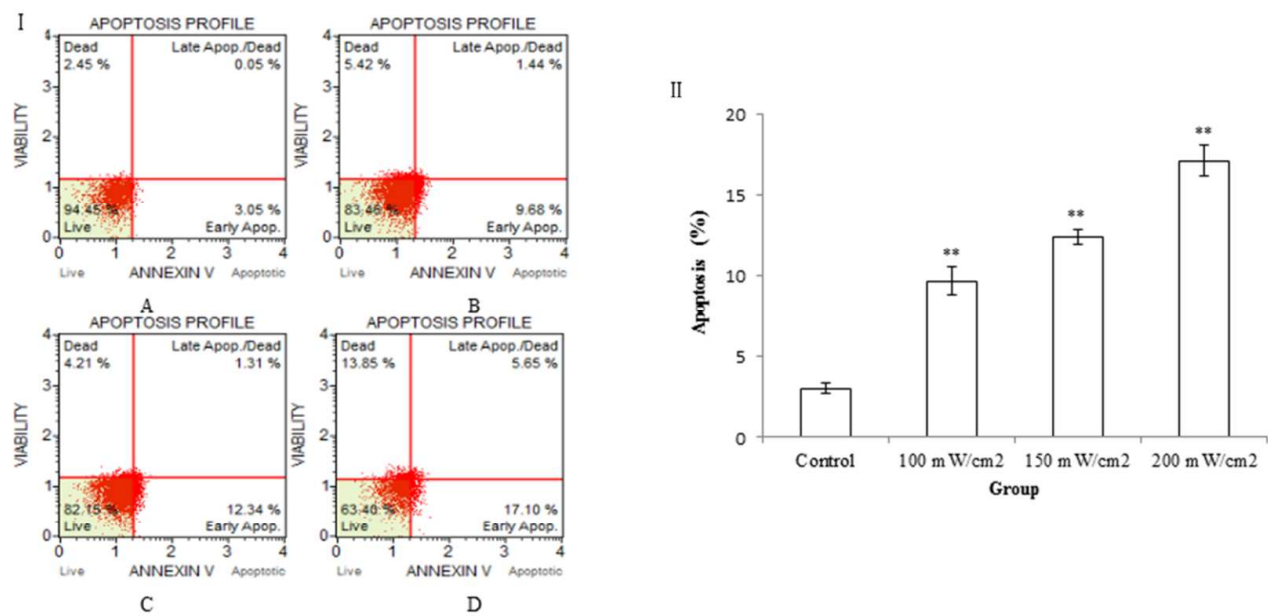

Fig. 6 

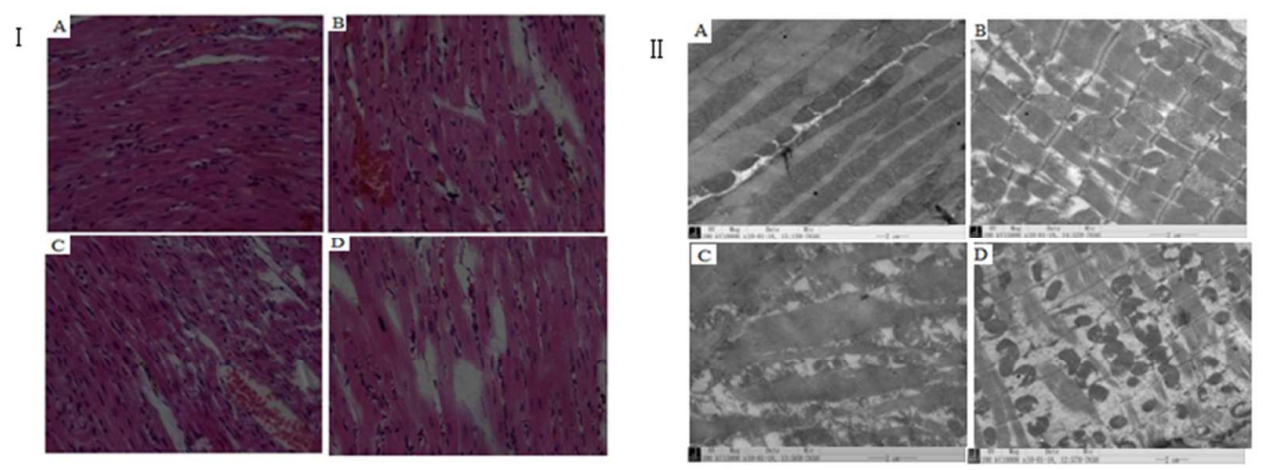

Fig. 7 
A

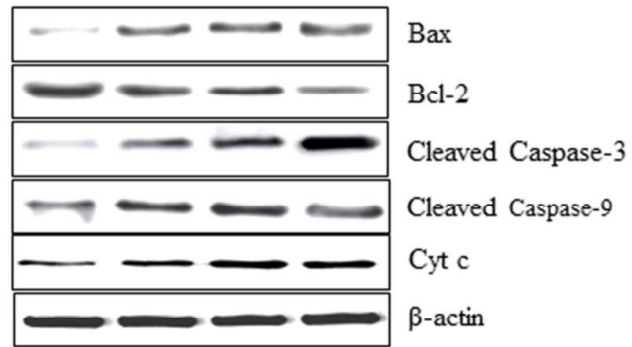

C
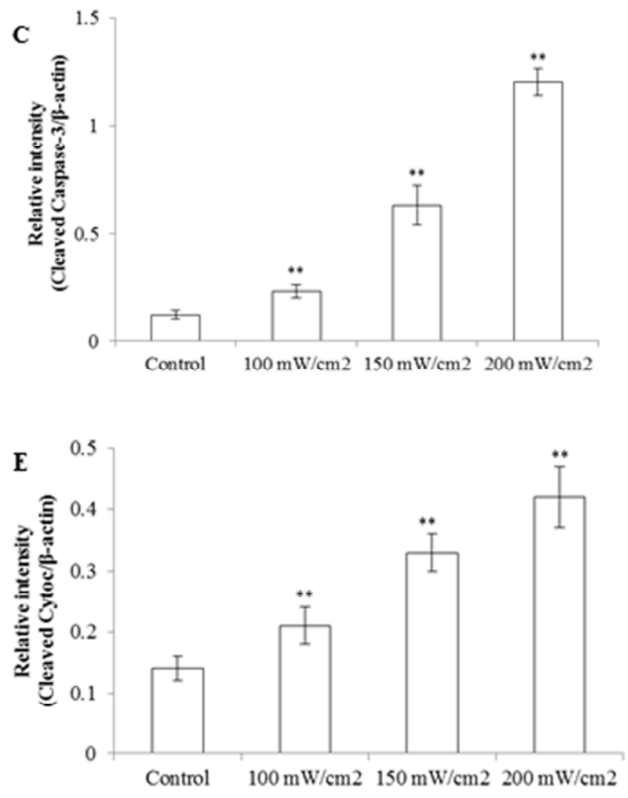
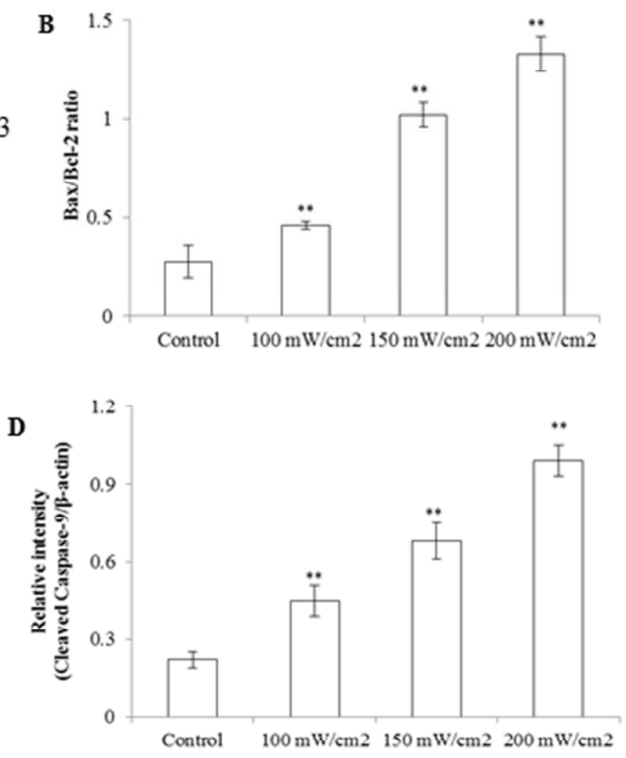

Fig. 8 

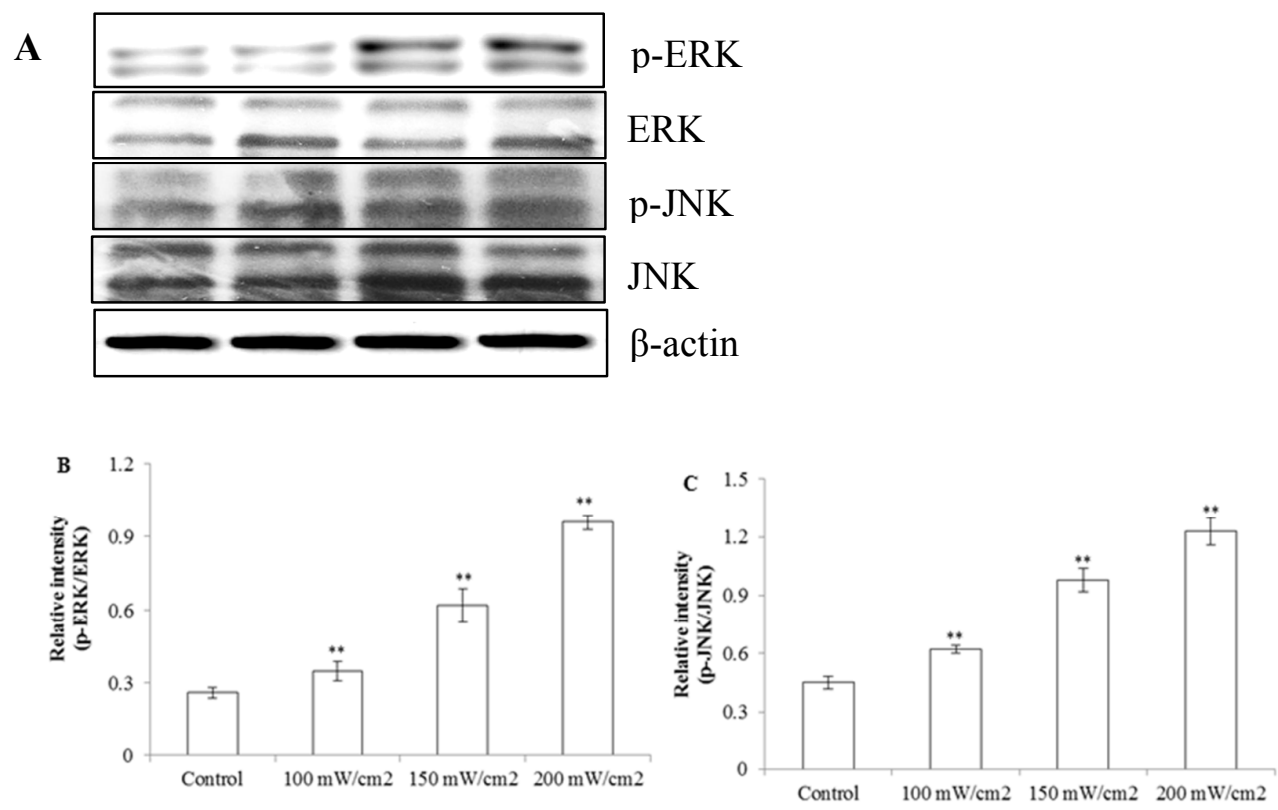

Fig. 9 